\title{
The Washington Center: A Grass Roots Approach to Faculty Development and Curricular Reform ${ }^{1}$
}

\section{Barbara Leigh Smith}

The Evergreen State College

Four years ago, an effort began in Washington State that dramatically altered our perceptions of what's possible in terms of revitalizing faculty and improving undergraduate education. It began modestly with two colleges working together; their efforts produced a model that became the foundation for a statewide consortium devoted to improving undergraduate education. Known as the "Washington Center for Improving the Quality in Undergraduate Education," the Center was conceived as a small scale, grass-roots-oriented effort emphasizing both faculty and curriculum development efforts. In just two years' time, the consortium tripled in size and was institutionalized with funding from the State Legislature. With headquarters at The Evergreen State College, it now serves 35 member institutions, both two-year and four-year colleges and universities and both public and independent institutions.

The story of the Washington Center raises important questions about our approaches to educational revitalization. It suggests that relatively low

${ }_{1}$ I am grateful to Jean MacGregor, Valerie Bystrom, and Pat Williams for their helpful comments in revising this manuscript.

From To Improve the Academy: Resources for Student, Faculty, and Institutional Development, Vol. 7. Edited by J. Kurfiss, L. Hilsen, S. Kahn, M.D. Sorcinelli, and R. Tiberius. POD/New Forums Press, 1988. 
cost approaches are available to create more coherent curriculum and more vital academic communities.

This article provides a historical overview of the Washington Center, a description of its current structure and its crucial features, and an analysis of its implications for educational reform and faculty revitalization. We believe the Washington Center offers a promising low-cost highyicld approach to educational improvement that could work in any state or region.

\section{Origins of the Washington Center}

The Washington Center's beginnings reflect a combination of fortuitous circumstance and creative entrepreneurship. Its origins trace back to February 1984, when a dean at Seattle Central Community College introduced his Instructional Council to the curriculum at The Evergreen State College, a college noted for its interdisciplinary curriculum and collaborative teaching. After spending a day visiting classes, the members of the Seattle Central Instructional Council were enthusiastic about Evergreen's approach and hoped to initiate a similar program to revitalize the liberal arts. One week after visiting the Evergreen campus, Seattle Central's Dean Ron Hamburg called to ask whether he could send two of his faculty members to Evergreen for a term to gain additional expertise with team teaching in one of Evergreen's integrated programs. Though spring quarter was only a month away, this was quickly arranged. Valerie Bystrom and Jim Baenan spent the next ten weeks at Evergreen team teaching with Thad Curtz, an Evergreen veteran, in a program called "Thinking Straight," which included literature, informal reasoning, anthropology, and writing.

Based on their experience at Evergreen, Bystrom and Baenan returned to Seattle Central to initiate an interdisciplinary program there. To assist the program in its early stages, two Evergreen faculty joined them while two other Seattle Central faculty journeyed to Olympia to continue the faculty exchange. They were the first in a long series of exchange faculty who would establish steadily decpening relationships among a variety of different institutions and faculty in Washington.

The new program at Seattle Central provided students and faculty with the opportunity to explore the theme of individualism in America through an intensive fifteen credit program taught by four faculty combining work in political economy, history, anthropology, literature, and the arts. The program was an immediate success. Students experienced a heightened sense of engagement and commitment, and retention was 
high. The most surprising aspect of the effort, though, was its enormous impact on faculty.

It was immediately and abundantly apparent that we had stumbled onto a highly effective low cost model for both curricular reform and faculty revitalization. In fact, the initial Seattle Central-Evergreen collaboration proved so appealing that neighboring institutions quickly became interested. Word spread through friendship networks in the community college system and a number of faculty members at other campuses expressed interest in establishing similar curricular efforts. Faculty exchanges were arranged among the various Seattle community colleges and were instrumental in initiating new programs at Bellevue and North Seattle Community College. Lower Columbia College, far to the south, sent an exchange professor to Evergreen, and the University of Washington, Western Washington University, and Seattle University joined as well.

Fueled by a $\$ 50,000$ grant from the Exxon Foundation to expand the model piloted through the Seattle Central-Evergreen relationship statewide, the Washington Center was launched with a half-time staff coordinator and modest funds for seeding projects, but interest was running so high, it quickly became apparent that we had a low cost model with large potential.

By the Spring of 1985 a growing constellation of institutions had come together to participate in the Washington Center. Although state funding was not provided initially, the State Legislature formally recognized the Washington Center in 1985 in the notes accompanying Evergreen's budget and other institutions were encouraged to participate. From 19851987, the Center's work continued to grow and prosper with the initial support from the Exxon Foundation and additional support from a $\$ 75,000$ grant from the Ford Foundation. Ford saw the Washington Center as a model collaborative effort to build ties between two and four year colleges.

\section{The Center's Structure and Administration}

By 1987 the consortium tripled in size with 32 participating institutions and new model programs in place at more than a dozen colleges and universities. After an unprecedented show of inter-institutional support from all levels of the participating institutions, the State provided funding in July 1987 with an annual budget of $\$ 200,000$. Half of these funds are pass-through funds to the member institutions to support a small seed grant program, faculty exchanges, travel, and seminars; the remaining funds support a small central staff of $21 / 4$ at Evergreen. The Center's style 
and focus remains adamantly face-to-face, small-scale and centered on the development of new curricular approaches (called learning communities), the arrangement of faculty exchanges, and the encouragement of collaborative efforts at building curricular coherence.

The Center's success reflects an unmet need for community and collegiality and a hunger for a kind of authentic dialogue that is too rare in many of our institutions. Because we believe in the importance of community, we prize our first-hand, face-to-face relationships with key faculty and administrators in each of our member institutions. The Center's Assistant Director, Jean MacGregor, and I have built creatively on our previous professional contacts in Washington state and the Northwest: institutional committees, the Pacific Northwest Writing Consortium, intercollege networks as diverse as counselors associations, developmental education groups, environmental studies associations, and a statewide community development network. We see ourselves as networkers building linkages, both new linkages and linkages between existing organizations with inter-related interests around the common goal of improving undergraduate education.

We use a variety of approaches to maintain firsthand contact with our participating schools. Center planning meetings, conferences, and seminars are carefully rotated to various sites around the state. We publish a quarterly newsletter to build connections. The newsletter features notable efforts in undergraduate education throughout the state, describes who is taking part in faculty exchanges, and indicates where model programs are taking place. A planning committee, consisting of pairs of faculty and administrators from eight of the participating institutions, oversees the work of the Washington Center. On this committee as well as others, attempts are made to preserve a good balance of veterans and newcomers. To increase local ownership and involvement, we create short and long term committees comprised of faculty members and administrators to plan almost all our efforts and events.

We also travel extensively throughout the State to maintain personal contact with faculty members and administrators on each campus. At the end of each quarter, we conduct team de-briefings of the faculty teams teaching in the interdisciplinary programs to maintain firsthand contact with the faculty and the programs.

Since we see face-to-face relations as crucial to the Center's success, we are concerned about the increasing size of the organization, sometimes half-jokingly talking about being buried in our own success. We're exploring various models for retaining the Center's grass roots personal contact while building more localized leadership on participating campuses. 


\section{Crucial Features of the Model: Structural Reform}

Two closely linked features define the Washington Center's approach to educational improvement: first, structural alteration of the educational environment into "learning communities" to enhance teaching and learning; and second, faculty exchanges into collaborative teaching situations. In this section we'll discuss structural change. The next section discusses the Washington Center's model of faculty exchanges.

A variety of different curricular models - all commonly referred to as "learning community" models - are being piloted by the colleges and universities associated with the Washington Center; these range from linked courses to the fully integrated coordinated studies program initiated at Seattle Central Community College and widely adopted at other institutions. "Learning community curricular designs" structure the educational environment to provide greater curricular coherence, a sense of purpose and group identity, more opportunities for active learning, and more intensive interaction between students and faculty. They redefine faculty roles and "encourage faculty members to relate to one another both as specialists and as educators...and help overcome the isolation of faculty members from one another and their students" (National Institute of Education, 1984 ). The faculty teaching in learning communities try to incorporate what is known about effective educational practice (See Chickering and Gamson, 1987 for a review of the principles underlying effective educational practice). All the model programs involve some degree of collaborative planning and teaching.

Interest in collaborative learning and learning communities is growing nationally. National visibility was heightened when the National Institute of Education's report, Involvement in Learning, recommended the establishment of learning communities as a means of developing a sense of purpose, reducing isolation of faculty and students, and encouraging integration in the curriculum. The Washington Center's work is related to a variety of other efforts in collaborative learning throughout the United States. For a discussion of a related group, Project CUE, Collaborative Undergraduate Education, see The Forum on Liberal Education, 1985; Esperian, Hill, and MacGregor (1986) review the federated learning community effort which is also comprised of kindred spirits.

The model used successfully for more than four years at Seattle Central directly replicates the Evergreen curricular approach. It is the model most typically used by Washington Center institutions. Instead of fulfilling general education requirements by taking a series of disciplinary courses, students in this model program enroll in an intensive 15 credit interdisciplinary program, called a "coordinated study program," for one 
or more quarters. This single program is the "full load" for both the faculty and students. The program typically enrolls 70-80 students; three or four faculty plan and teach the program together. The programs are thematic, and they cover a variety of different subject areas. Previous coordinated studies programs at Seattle Central include "The Making of Americans: Individualism" (political economy, art, literature, and history); "Power and the Person" (visual art, philosophy, music, literature); "Modern Thought, Images and Feeling: Europe 1900-1940" (philosophy, history, English, art history); and "Science Shakes the Foundations: Perspectives on Marx, Dickens, and Darwin" (political economy, English literature, biology, history). Although the programs typically began in the academic transfer divisions of the participating institutions, they quickly spread to developmental and vocational areas.

Conceiving of general education in terms of cultivating students' integrative abilities, the emphasis in these programs is on developing students' analytical and synoptic skills and their capacity to deal with complex issues from a multi-disciplinary point of view. Since these programs always include extensive work in written and oral communication, they frequently fulfill requirements in composition. Though they are somewhat more expensive than the "average" community college course at the freshman level, retention is high. Preliminary information on the students' level of cognitive development suggests that the coordinated studies programs are highly effective in fostering higher order thinking (MacGregor, 1987).

The Washington Center's success is partly due to its stress on a variety of curricular alternatives and the importance of local adaptations. We emphasize that there are multiple curricular designs for building curricular coherence and integration, and continually draw on the growing local and national network of learning community models to present a large menu of design possibilities. The Center's participating institutions have responded just as we'd hoped, by designing their own local adaptations. At Shoreline Community College, for example, writing and critical reasoning across the curriculum is a major focus and much of the effort is directed at linking composition and content courses. At Eastern Washington University, the University of Washington, and Western Washington University, the search for a more coherent approach to curriculum is being pursued through "freshmen interest groups," an approach that encourages students to register for thematically clustered courses.

To support these efforts, the Center collects and disseminates information about promising approaches throughout the United States and conducts quarterly seminars on various topics relating to the improvement of undergraduate education, such as active approaches to learning, writ- 
ing across the curriculum, and similar themes. News of these curricular approaches doesn't just flow from the Washington Center; the participating institutions now frequently share perspectives directly. Inter-institutional faculty exchanges are one of the Center's most powerful means of developing new curricula and promoting the transfer of knowledge between faculty members.

\section{Crucial Features of the Model: Faculty Exchanges as a Vehicle for Curricular Transformation}

The Washington Center acts as a statewide broker for inter-institutional faculty exchanges. Unlike most faculty exchange programs, the Washington Center's exchanges are not viewed simply as opportunities for faculty members to teach their usual courses in another institutional setting. Instead, the exchange program complements and extends the Center's curricular reform effort by placing exchange faculty, wherever possible, into team teaching situations in new model programs. The exchange program thereby amplifies the process of educational reform and the transfer of knowledge between individuals and institutions as newcomers learn from veterans and take it back to their home institutions.

Teams often include one exchange faculty member from another institution, one veteran from a previous learning community program, and two newcomers to collaborative teaching. Many of the institutions try to rotate various faculty members through the programs to broaden the impact on the institution as a whole, but a balance of newcomers and relatively experienced faculty members is also important to the programs' success.

The Washington Center brokers these inter-institutional teaching exchanges and provides a small housing stipend if relocation is necessary. No additional costs are incurred if the exchange is a reciprocal one. Since the exchange is typically into a team taught collaborative program, it usually isn't necessary to find exchange professors who are disciplinary equivalents - often an obstacle to conventional faculty exchange programs. If a reciprocal exchange can't be arranged, the Center makes a small ( $\$ 3000-\$ 5000$ per quarter) contribution towards replacement costs. In arranging the exchanges, paperwork and red tape are purposely kept to a minimum. At most of the participating institutions, both the deans and division chairs actively support the exchange program and are highly responsive to faculty interests. By June 1989 we estimate that more 
than 160 faculty in a dozen institutions will have been involved with the Washington Center faculty exchange effort - either as actual exchange faculty or team teaching with a visitor from another school.

\section{Exchanges as a Vehicle for Inter-Institutional Community}

Inter-institutional faculty exchanges in collaborative teaching settings have their own dynamics, in terms of both possible obstacles and rewards. In addition to the usual boundaries that separate faculty within an institution - departmental, historical, spatial, etc. - there are often substantial institutional boundaries within a state's higher education system relating to status, priorities, institutional culture, location, and resources. Especially pronounced are perceived differences between two and four year institutions and the private and public sector. Too often, as we squabble for status and resources, our differences capture our attention more than our commonalities and shared concerns. Indeed, this competitive pattern of thinking is so well entrenched that during the Washington Center's earliest days, we were often greeted with disbelief at the apparent act of altruism the organization represented!

Many faculty members report an initial sense of anxiety about entering a new institution, especially if it is a different type of setting than their home campus. Teaching in front of ones' colleagues is also disquieting at first, but most participants quickly find that team teaching provides an important social and intellectual base from which to experience the new community without suffering the isolation of being a newcomer and an outsider. Exchange faculty say it is an enormously important learning experience for them, often more stimulating than a sabbatical. Most leave the exchange relationship with a new sense that the higher education system is, in fact, one educational community with many shared interests. The relationships among new-found inter-institutional colleagues usually persist beyond the term of the exchange itself, as a growing circle of faculty and administrators continue to interact through quarterly conferences, seminars and the annual statewide curriculum planning retreat that the Washington Center organizes and sponsors.

\section{Implications for Faculty Development}

Collaborative teaching and inter-institutional exchanges clearly offer great rewards to many people. In many institutions, there is little faculty 
interaction across departmental boundaries; reward systems, spatial assignments, curricular patterns, and time schedules combine to make faculty interaction, especially around pedagogical or intellectual ideas, rare if not nonexistent. Collaborative teaching can be powerful in bringing people together who were previously only passing acquaintances. Faculty generally report that the experience substantially alters their subsequent patterns of collegial interaction and gives them an enhanced sense of camaraderie and respect for one another. These new efforts are also powerful in terms of building collaboration and new rapport within institutions between faculty and administrators as they work together to try and adopt new approaches.

Our positive experience with faculty exchanges and collaborative teaching offers a suggestive contrast to the current literature which paints a discouraging portrait of the nation's faculty (Seidman, 1985; Boyer, 1987; Bowen and Schuster, 1987). This contrast offers important insights into alternative ways to improve undergraduate education and promote faculty vitality.

Our experience suggests that some of the simplest approaches to maintaining the intellectual vitality of our faculty are often overlooked. While improving the material conditions of our work may be necessary, it certainly won't be enough. Finding opportunities and institutional structures that empower individuals and allow them to continue to learn and re-create is also vitally important. Simply providing creative opportunities and structures to work together is apparently one of the keys.

A recent book on decision-making by Todd Sloan is suggestive in thinking about the dynamics of maintaining faculty and institutional vitality. He stresses the social dimensions of life's choice making and the importance of understanding the context of the individual (Sloan, 1987). Sloan points out that all of us experience everyday life as a structure with great continuity because of the regularity in the contexts and the relationships we encounter. We often come to "frame" or see our life choices as more limited than they are, in fact; the regularity of the overall structure and situation reinforces this limiting conception. Perhaps because of its unusual boundary crossing capacity, the Washington Center program seems to have a peculiar ability to encourage people and institutions to "break frame."

The repetitiveness and mind-deadening redundancy many experience in their work is a major problem in higher education; it is a hidden disease slowly eating away at faculty vitality in many of our institutions. One faculty member told us with great precision that she will face $125 \mathrm{sec}$ tions of English 101-102 before retirement; another can precisely forecast the number of freshman essays she has left to read. In a reflective 
autobiographical essay, another wrote about his fear that he "..is becoming the kind of faculty member that administrators shudder at getting stuck with; the kind that he himself shudders at getting stuck with."

Many of the people with whom we work also describe their work and their institutional relations as reaching a certain "plateau" after a number of years; this plateau often became a ceiling on their subsequent relationships and aspirations. This ceiling takes many different forms. It defines what we teach and how. It defines roles and relationships - between departments, among faculty colleagues, and relationships with administrators. Most importantly, this ceiling defines what is possible and what isn't possible. It removes many of the surprises and puzzles from everyday life.

Faculty exchanges and collaborative teaching provide important opportunities for "re-framing" simply by altering the routine work environment and social relations in substantial ways.

The social context is dramatically re-defined by collaborative teaching and cross-institutional work and new conceptions of the educational community are created. Collaborative teaching, especially across institutional boundaries, disrupts old patterns and expectations. It presents genuine puzzles and new situations. In doing so, we also become more aware of the unproductive routines we often fall into. In Sloan's terms, the experience allows us to "re-frame" our work and our institutional relationships. One of the members of our Planning Committee put this in a slightly different way: he suggested that the Washington Center works quite simply because it turns teachers (and administrators) back into learners.

It is probably significant that faculty exchanges and collaborative teaching are of special interest to mid-career faculty, who have achieved institutional security and are often highly skilled teachers. These faculty have many talents, commitments, and needs that are ignored in our institutions and largely unexplored in the current literature on faculty development.

Mid-career faculty are at a stage when they need new challenges. "When you reach a certain level of proficiency," one of them recently said, "you get kind of afraid that you are losing your edge if you don't see new challenges." Our experience also suggests that mid-career faculty are ready and eager to make more substantial commitments to long term institutional improvement. After seeing their joy and eagerness in assuming more leadership, we wonder why it hasn't happened sooner! Perhaps institutions underestimate this interest and willingness because they assume that faculty commitments are largely to national discipline-based cultures and associations. While these national affiliations are certainly important, they don't provide the day-to-day sustenance that a more local institution- 
al culture and sense of community provides. Faculty may, in fact, turn to national associations in desperation because the local culture does not provide a sense of community and commitment.

Our experience compels us to think more broadly about institutional roles and what we mean by leadership. When college communities think of leadership, it is usually in terms of administrative leadership and in a single institutional setting. We seldom think in terms of leadership in the classroom. We almost never think of it across institutions. Team teaching gives mid-career faculty the opportunity to serve as mentors and leaders in the most useful possible place - the classroom itself.

Perhaps the most important aspect of collaborative teaching for both junior and senior faculty is the fact that the new model curricula put the teaching faculty totally in charge of their teaching, in terms of both content and structure. They are jointly empowered to create something new that is substantively and pedagogically sound and stimulating. Equally important, the process of designing and delivering this curriculum entails risk-taking, and it is public and collegial. It is not subject to the committee "brokering" that frequently attends and undermines meaningful curricular reform efforts. The attractiveness of the opportunity to create a more emergent curriculum can perhaps be fully appreciated only when it is contrasted with the redundancy of much college teaching (especially in community colleges too often narrowly circumscribed by transfer agreements), the loneliness and isolation many faculty apparently feel, and the bureaucratization in many institutions that has undermined people's sense of personal power and their sense of community.

This more emergent approach to curriculum requires trust in the good judgment of the participating faculty members, and perhaps this act of trust also accounts for the success of the new collaborative programs and the Washington Center. In our experience, this trust has not been abused. Generally speaking, educators want to teach something worthwhile, that they themselves find interesting. They have a conception of what this should be. Working with faculty in other disciplines provides a new challenge that in no way replicates the curriculum committee process of "assembling" a general education curriculum. After watching general education committees struggle for years to make relatively minor reforms, it is surprising to see how quickly a team of four good faculty will come up with an exciting and substantive general education program for a quarter-or year-long program. Inter-institutional transfer of these interdisciplinary programs is not usually a problem. Most states and institutions allow considerable flexibility in their transfer policies and general education programs, and the new coordinated studies program can easily fit within most general guidelines. Even in states with very restrictive 
policies, integrated programs have been developed. The Quanta program at Daytona Beach Community College is a good example of creatively building an interdisciplinary learning community type program within rigorous state requirements about transfer and the Associate of Arts degree.

\section{A Grass Roots Model for Reform}

Our four-year history with this collaborative effort has led us to "reframe" our own thinking, as well, about curricular reform and faculty development. Our experience suggests that it's possible to create local cross institutional professional communities focused on improving undergraduate education. This model offers a promising and relatively low-cost approach to faculty revitalization and to exploring models for curricular reform. It has opened up a productive dialogue about undergraduate education within and among our institutions that extends considerably beyond the learning community model programs themselves. By providing structures and opportunities for bringing people together, the Washington Center hopes to encourage statewide interest in improving undergraduate education. To a remarkable extent, it has been successful in doing this, and faculty and administrators have found a new sense of common enterprise by joining hands in this effort. We have done this by operating from the assumptions that, despite our differences, we are one educational community with many overlapping interests and concerns, that we can make substantial accomplishments together that we cannot make alone, and that small scale, grass roots and collaborative approaches are the best places to begin.

\section{References}

Bowen, H. R. (1986). American professors: A national resource imperilled. New York: Oxford University Press.

Boyer, E. (1987). College: The undergraduate experience in America. New York: Harper and Row Publishers.

Chickering, A. and Gamson, Z. (1987). "Seven principles for good practice in undergraduate education." American Association for Higher Education Bulletin, March 3-7.

Forum for Liberal Education (1985). "Collaborative learning." Vol. 8, No.

2 (entire issue). 
Esperian, J., Hill, P. J. and MacGregor, J. (1986). "Bibliography on the Federated Learning Communities and ralated programs." Olympia, Washington: The Evergreen State College.

MacGregor, J. (1987). "Intellectual development of students in learning community programs 1986-87.” Olympia, Washington: Washington Center for Undergraduate Education.

National Institute of Education (1984). Involvement in leaming: Realizing the potential of higher education. Washington, D.C.

Seidman, E. (1985). In words of the faculty: Perspectives on improving teaching and educational quality in community college. San Francisco, California: Jossey Bass Publishers.

Sloan, T. (1987). Deciding: Self deception in life choices. New York: Methuen and Co. 